\title{
Fat-free weight prediction in morbidly obese females
}

This article was published in the following Dove Press journal: International Journal of Nephrology and Renovascular Disease 18 November 2011

Number of times this article has been viewed

\author{
Ion D Bucaloiu' \\ G Craig Wood ${ }^{2}$ \\ Evan R Norfolk' \\ Christopher D Still ${ }^{3}$ \\ James E Hartle' \\ Robert M Perkins ${ }^{4}$ \\ 'Department of Nephrology, \\ Geisinger Medical Center, Danville, \\ $\mathrm{PA} ;{ }^{2}$ Biostatistics and Research \\ Data Core, Henry Hood Center for \\ Health Research, Geisinger Medical \\ Center, Danville, PA; ${ }^{3}$ Center for \\ Nutrition and Weight Management, \\ Geisinger Medical Center, Danville, \\ PA; ${ }^{4}$ Department of Nephrology \\ and Henry Hood Center for Health \\ Research, Geisinger Medical Center, \\ Danville, PA, USA
}

Purpose: Precise estimation of creatinine clearance in obese individuals relies on the appropriate assessment of lean body weight (LBW). Anthropometric methods of predicting LBW have not been validated in morbidly obese populations.

Patients and methods: Using an existing dataset of anthropometric data for a female cohort with morbid obesity who had undergone measured FFW with dual energy absorptiometry, we evaluated the performance of five previously reported estimating equations for the prediction of LBW. Linear regression was used to derive a new LBW prediction formula and was then compared with the other formulae.

Results: Seventy females (mean [standard deviation] age, weight, and body mass index 43.0 [11.0] years, 128.1 [13.8] kg, and 48.3 [4.8] kg/m², respectively) were identified. LBW as estimated by the method of Garrow and Webster correlated well $(r=0.87)$ with measured mass while demonstrating the highest accuracy, best precision, and smallest bias $(93 \%, 2.1 \mathrm{~kg}$, and $2.9 \mathrm{~kg}$, respectively; $P<0.0001$ for all comparisons). The derived formula further improved bias, precision, and accuracy.

Conclusion: Among females with morbid obesity, most previously reported estimating equations for LBW predicted FFW poorly. These findings have important clinical implications for the assessment of kidney function and for safe and effective drug dosing.

Keywords: body composition, body weight, creatinine clearance, kidney function, lean body mass, obesity, pharmacokinetics

\section{Introduction}

At extremes of weight, misapplication of commonly used clinical tools developed in normal-weight populations may have serious adverse consequences. ${ }^{1}$ There is a need for clinically useful and accurate methods of estimating renal function among patients with morbid obesity (body mass index $[\mathrm{BMI}] \geq 40 \mathrm{~kg} / \mathrm{m}^{2}$ ) for the purpose of safe and effective drug dosing, monitoring of kidney function longitudinally, and effective risk counseling. In this population, estimation of renal function is problematic, as commonly used formulae perform poorly at extremes of weight. ${ }^{2-4}$ Estimations of creatinine clearance using adjusted body weight (ABW) may represent a better assessment of kidney function than estimations of glomerular filtration rate using the Modification of Diet in Renal Disease estimating formula ${ }^{5}$ among patients with morbid obesity. Recently, several investigators have reported improved renal function estimates in obese (BMI $\left.\geq 30 \mathrm{~kg} / \mathrm{m}^{2}\right)$ individuals using the Cockcroft-Gault creatinine clearance formula ${ }^{6}$ with adjustment for lean body weight (LBW) either by direct fat-free weight (FFW) measurement or by way of an estimating formula. ${ }^{7,8}$
Correspondence: Ion D Bucaloiu Department of Nephrology, Geisinger Medical Center, MC 13-48, 100 North Academy Ave, Danville, PA 17822, USA $\mathrm{Tel}+\mathrm{I} 57027 \mathrm{l} 6393$

$\mathrm{Fax}+|57027| 5623$

Email idbucaloiu@geisinger.edu 
Whether this applies to patients with morbid obesity is not clear, as the relationship between BMI and lean weight is not linear. 9

Although direct measurement of FFW can be performed in several ways - to include dual energy absorptiometry (DEXA) - such methods are not practical for routine clinical use, due to complexity and cost. ${ }^{10-12}$ It is expected that LBW will overestimate fat-free mass (FFM) by 3\%-5\%, given that measurement of the latter does not include the normal adipose tissue surrounding muscle and nerves in a lean individual. However, use of LBW could serve as a clinically useful surrogate for FFM for calculation of clearances of endogenous creatinine, as this substance distributes mainly in muscle and interstitial and vascular spaces., ${ }^{3,13}$ Various formulae for estimating LBW have been reported, ${ }^{14-21}$ but none has been developed or validated for specific use in a population of patients with morbid obesity.

This study evaluates the ability of previously reported alternative body size descriptor (ABSD) estimating formulae to predict measured FFW by DEXA in a cohort of female, morbidly obese patients enrolled in a weight management program at a tertiary medical center in Central Pennsylvania. We did not limit the identification of previously reported formulae to those estimating LBW only, as the primary goal of this study was to identify a clinically useful estimating tool that could be employed in the Cockcroft and Gault creatinine clearance equation. As a secondary goal, we wished to improve upon the estimation of LBW in our own population through the development of a novel LBW estimating equation based on anthropometric and clinical data from our study population.

\section{Material and methods Subjects}

The study was reviewed and approved under "exempt" status by the Geisinger Medical Center Institutional Review Board in May 2010. The study uses existing data from a cohort of 70 adult (aged $\geq 18$ years) morbidly obese (BMI of $\geq 40.0 \mathrm{~kg} / \mathrm{m}^{2}$ ) female patients who participated in a feasibility project evaluating the use of preoperative DEXA body composition scanning between May 2005 and January 2006 while undergoing evaluation in a comprehensive weight management clinic prior to bariatric surgery at Geisinger Medical Center. ${ }^{22}$ The database that served as the source for this study includes demographic, clinical, outcomes, and claims information, including detailed anthropometric measurements, and has been previously validated. ${ }^{23-27}$

\section{Anthropometric measurements}

Body composition measurements (fat mass, lean mass, and bone mass) were made with a Hologic Series 4500 W Fan Beam X-ray Bone densitometer (Hologic, Inc Bedford, MA). Measurements were performed on subjects following the removal of all metal accessories. Scanners were calibrated daily prior to patient use, using standard phantom measurements. Patients were weighed at each clinic visit in the weight management clinic wearing hospital gowns. All weights are expressed in kilograms $(\mathrm{kg})$. Height $(\mathrm{Ht})$ in centimeters $(\mathrm{cm})$ was measured at the initial clinic visit and not repeated subsequently. From the above measurements, $\mathrm{BMI}=\mathrm{Wt} /(\mathrm{Ht} \times 100)^{2}$ and ideal body weight $(\mathrm{IBW})$ $(\mathrm{IBW}=45.4+0.89 \times[\mathrm{Ht}-152.4])^{28}$ were calculated. LBW in the context of this study refers to the weight of lean tissue, including the normal amount of fat contained in a lean individual (approximately 3\% in males and 5\% in females), ${ }^{17}$ whereas FFW refers to the weight of lean tissue stripped of all fat, including the fat content of nervous system, cell membranes, and bone marrow.

\section{Selection of LBW estimating equations and assessment of performance}

In order to identify previously reported estimations for LBW, we performed a literature search using Ovid MEDLINE ${ }^{\circledR}$ (1950 to July Week 2, 2010) using the following search terms: body composition, morbid obesity, obesity, kidney function tests, glomerular filtration rate, lean body weight estimation, creatinine clearance, and pharmacokinetics. References of pertinent articles were also searched for studies describing LBW estimating equations for use in obese subjects. No method of estimating LBW exclusively in morbidly obese subjects was identified; five ABSD equations for the nonmorbidly obese populations were identified and assessed for the purposes of this analysis (Table 1). For the ABSD formula initially proposed by Karkeck, ${ }^{15}$ two versions were used in this study, one using the original reported equation with a correction factor of 0.25 , and a second with a correction factor of 0.5 , as the latter reportedly improves caloric expenditure prediction and drug clearance in obese individuals when compared with the original equation. ${ }^{16,29}$ In addition, a sixth equation developed in our patient population was used to estimate FFW (FFW [GEISINGER] $)$. Thus, each of our subjects had one measured FFW (FFW $\left.{ }_{[\mathrm{DEXA}]}\right)$ and six LBW estimations, each using a different ABSD.

To compare the ability of each individual ABSD to predict $\mathrm{FFW}_{[\mathrm{DEXA}]}$, we calculated correlation, bias, precision, and accuracy. 


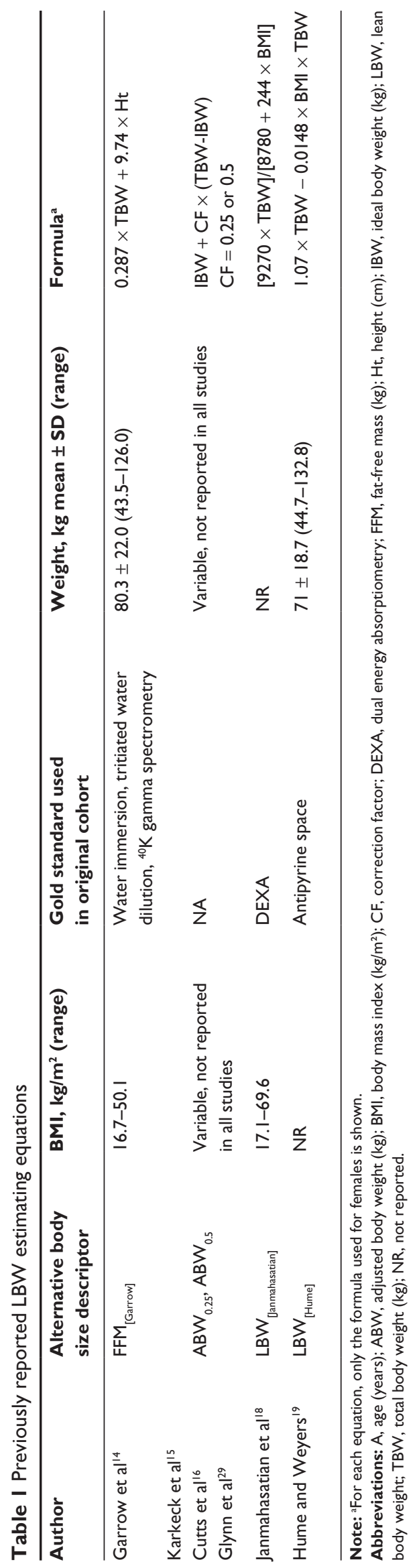

\section{Statistical analyses}

Continuous data are reported as means and standard deviations (SDs), whereas categorical variables are expressed as frequencies. When appropriate, the distributions of each continuous variable were examined for a symmetrical, bell-shaped distribution (ie, the normal distribution) and homoscedasticity (ie, equality of variance). Bias, precision, accuracy, and the Pearson correlation coefficient $(r)$ were calculated for each estimating equation using $\mathrm{FFW}_{[\mathrm{DEXA}]}$ as the gold standard. Bias was defined as the absolute value of the difference between the estimated LBW and FFW ${ }_{\text {[DEXA] }}$ (also known as absolute bias). Precision was defined as the $\mathrm{SD}$ of the absolute bias. Accuracy was calculated as the percentage of patients who had an estimated FFM within $10 \%$ of the $\mathrm{FFW}_{\text {[DEXA] }}$.

Differences in bias and accuracy were compared between ABSDs using a paired $t$-test and McNemar's test. This was done by comparing the ABSD formula that performed the best (ie, with the least bias or with the highest accuracy) against all other ABSD formulae in a pairwise fashion. Differences in precision among the various ABSDs were not tested. To determine whether estimating formula performance was similar for different levels of obesity, the bias, precision, accuracy, and correlation coefficient were also calculated after stratifying by BMI subcategories $\left(40.0-44.9 \mathrm{~kg} / \mathrm{m}^{2}\right.$, $45.0-49.9 \mathrm{~kg} / \mathrm{m}^{2}, \geq 50.0 \mathrm{~kg} / \mathrm{m}^{2}$ ).

Agreement between measured and estimated LBW values was assessed using the method of Bland and Altman, ${ }^{30}$ in which the difference between estimated LBW and FFW ${ }_{\text {[DEXA] }}$ is plotted against the $\mathrm{FFW}_{\text {[DEXA] }}$. A positive difference suggests an overestimation of the formula, whereas a negative difference suggests an underestimation. The limits of agreement were calculated as the bias plus two times the precision.

In exploratory analysis, linear regression was used to determine whether a new ABSD could be derived that outperformed existing ABSDs. BMI, total body weight (TBW), $\mathrm{Ht}$, and IBW were considered for inclusion in the regression model and the minimal subset of measures that maximized the model $r$-squared was retained.

All statistical analyses were performed using $\mathrm{SAS}^{\circledR}$ software (version 9.2, Cary, NC).

\section{Results}

Seventy morbidly obese female patients underwent body composition DEXA. Patient characteristics and major comorbid conditions are presented in Table 2. All patients were Caucasian, with a mean age of 43 years. Thirty-six percent 
Table 2 Characteristics of population of morbidly obese female patients undergoing DEXA $(n=70)$

\begin{tabular}{|c|c|}
\hline Characteristic & Mean (SD) \\
\hline Age $(y)$ & $43(\mathrm{II})$ \\
\hline Weight (kg) & I28.I (13.8) \\
\hline Height $(\mathrm{cm})$ & $162.8(5.4)$ \\
\hline Serum creatinine (mg/dL) & $0.8(0.2)$ \\
\hline BMI $\left(\mathrm{kg} / \mathrm{m}^{2}\right)$ & $48.3(4.8)$ \\
\hline Waist circumference $(\mathrm{cm})^{\mathrm{a}}$ & I28.I (10.2) \\
\hline $\mathrm{FFW}_{[\text {[DEXA] }}(\mathrm{kg})$ & $63.4(6.9)$ \\
\hline Comorbid conditions & $\mathbf{N}(\%)$ \\
\hline Hypertension & $25(36)$ \\
\hline Hyperlipidemia & $22(31)$ \\
\hline Diabetes & $15(2 \mid)$ \\
\hline Obstructive sleep apnea & $6(9)$ \\
\hline Cerebrovascular disease & $2(3)$ \\
\hline Atherosclerotic cardiovascular disease & $\mathrm{I}(\mathrm{I})$ \\
\hline Chronic renal disease & $\mathrm{I}(\mathrm{I})$ \\
\hline
\end{tabular}

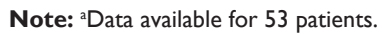

Abbreviations: BMI, body mass index $\left(\mathrm{kg} / \mathrm{m}^{2}\right)$; DEXA, dual energy absorptiometry; FFW, fat-free weight $(\mathrm{kg})$

had hypertension, one-third had hyperlipidemia, and $21 \%$ were diabetics. The majority $(94 \%)$ of patients had preserved renal function (estimated glomerular filtration rate) calculated using the four-variable Modification of Diet in Renal Disease equation ${ }^{31}\left(>60 \mathrm{~mL} / \mathrm{min} / 1.73 \mathrm{~m}^{2}\right)$. The remaining four patients had estimated glomerular filtration rates $42.9,43.7,51.2$, and $55.4 \mathrm{~mL} / \mathrm{min} / 1.73 \mathrm{~m}^{2}$, respectively.

Results of individual formula performance are presented for the overall population in Table 3 and for subcategories of BMI in Table 4. FFM ${ }_{\text {[Garrow] }}$, the ABW formulae, and $\mathrm{LBW}_{\text {[Janmahasatian] }}$ correlated well with $\mathrm{FFW}_{\text {[DEXA] }}(r>0.80)$. In contrast, $\mathrm{LBW}_{[\text {Hume] }}$ and $\mathrm{LBM}_{[\text {Moore] }}$ correlated poorly.

Table 3 Correlation, bias, and accuracy of reported estimating equations for LBW compared with DEXA-derived lean body weight for female patients with morbid obesity (BMI > $\left.40 \mathrm{~kg} / \mathrm{m}^{2}\right)$

\begin{tabular}{lllll}
\hline \multirow{2}{*}{ Formula } & \multicolumn{4}{l}{ All patients $(\mathbf{n}=\mathbf{7 0})$} \\
\cline { 2 - 5 } & Bias $^{\mathbf{a}}$ & Precision $^{\mathbf{b}}$ & Accuracy $^{\mathbf{c}}$ & $\mathbf{r}$ \\
\hline $\mathrm{FFM}_{[\text {Garrow] }}$ & 2.9 & 2.1 & $93 \%$ & 0.87 \\
$\mathrm{ABW}_{0.25}$ & 9.7 & 3.8 & $17 \%$ & 0.84 \\
$\mathrm{ABW}_{0.5}$ & 28.0 & 4.1 & $0 \%$ & 0.87 \\
$\mathrm{LBW}_{\text {[anmahasatian] }}$ & 6.0 & 3.6 & $54 \%$ & 0.85 \\
$\mathrm{LBW}_{\text {[Hume] }}$ & 18.7 & 10.0 & $4 \%$ & -0.15 \\
$\mathrm{FFW}_{\text {[GEISINGER] }}$ & 2.8 & 1.8 & $97 \%$ & 0.87 \\
\hline
\end{tabular}

Notes: ${ }^{\text {aBias }}=$ mean absolute bias (mean absolute value of difference between

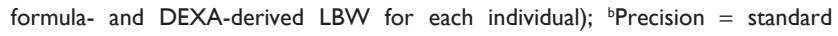
deviation of mean absolute bias; 'Accuracy = percentage of estimations within $10 \%$ of the FFW ${ }_{[D E X A]}$.

Abbreviations: ABW, adjusted body weight $(\mathrm{kg})$; BMI, body mass index $\left(\mathrm{kg} / \mathrm{m}^{2}\right)$; DEXA, dual energy absorptiometry; FFM, fat-free mass (kg); FFW, fat-free weight (kg); LBW, lean body weight $(\mathrm{kg})$.
Beyond correlation, the performance of equations other than $\mathrm{FFM}_{[\text {Garrow] }}$ was quite poor. The overall mean bias was smallest for the $\mathrm{FFM}_{[\text {Garrow] }}$ equation $(P<0.0001$ for pairwise comparisons). This equation also had the highest accuracy $(P<0.0001$ for pairwise comparisons) and best precision. Bias, precision, and accuracy were lower for the BMI-based equations $\left(\mathrm{LBW}_{\text {[Janmahasatian] }}\right.$ and $\left.\mathrm{LBW}_{\text {[Hume] }}\right)$. $\mathrm{LBW}_{\text {[Janmahasatian] }}$ did maintain its level of accuracy in BMI categories between $40.0-44.9 \mathrm{~kg} / \mathrm{m}^{2}$ and $45.0-49.9 \mathrm{~kg} / \mathrm{m}^{2}$ but not in subjects with BMI $\geq 50.0 \mathrm{~kg} / \mathrm{m}^{2}$.

A Bland-Altman plot for the $\mathrm{FFM}_{[\text {Garrow] }}$ equation is shown in Figure 1. There is an inverse relationship between bias and incremental measured FFW $(r=-0.73)$.

In regression analysis performed to identify an improved prediction formula, the combination of body composition measures that optimized the prediction of FFW was TBW and $\mathrm{Ht}$. The resulting equation was $\mathrm{FFW}_{\text {[GEISINGER] }}=-11.41+$ $(0.354 \times \mathrm{TBW})+(11.06 \times \mathrm{Ht})$. Though not significantly different from $\mathrm{FFM}_{[\text {Garrow] }}$, this equation had the least bias, the best precision, and the highest accuracy.

\section{Discussion}

LBW estimation in morbidly obese individuals presents unique challenges. In our exclusively Caucasian female population, not all previously reported ABSD estimating formulae performed well for the determination of FFW as measured by DEXA body composition testing.

One estimating formula in particular, $\mathrm{FFM}_{[\text {Garrow] }}$, outperformed others. This regression equation was developed in a predominantly $(81 \%)$ female population with mean (SD) BMI $27.2(7.8) \mathrm{kg} / \mathrm{m}^{2}$ against a gold standard consisting of the average body fat measurement obtained by three different methods (tissue density, total body water using a tritiated water dilution method, and total body potassium using the ${ }^{40} \mathrm{~K}$ isotope gamma spectrometry method) ${ }^{14}$ It is interesting that each of these methods measures a slightly different lean weight, making the combination of the three methods a potentially robust assessment of the true lean mass. In our cohort, this equation demonstrated the most optimal performance characteristics for the overall population with morbid obesity as well as within each subcategory of BMI.

Other ABSDs performed suboptimally, though several formulae incorporating BMI ( $\mathrm{LBW}_{\text {[Janmahasatian] }}$ and $\left.\mathrm{LBW}_{\text {[Hume] }}\right)$ performed modestly well across some of the study metrics. The formula developed by Janmahasatian et a ${ }^{18}$ was developed using $\mathrm{FFW}_{[\mathrm{DEXA}]}$ as a gold standard in a gender-balanced Australian population that was predominantly (70\%) overweight (BMI $\geq 25$ ). This equation has subsequently been 
Table 4 Correlation, bias, precision, and accuracy of reported estimating equations for LBW compared with dual energy absorptiometryderived lean body weight for female patients with extreme obesity (BMI $>40 \mathrm{~kg} / \mathrm{m}^{2}$ ), by BMI category

\begin{tabular}{|c|c|c|c|c|c|c|c|c|c|c|c|c|}
\hline \multirow[t]{2}{*}{ Formula } & \multicolumn{4}{|c|}{$\begin{array}{l}\text { BMI 40.0-44.9 } \\
(\mathrm{N}=20)\end{array}$} & \multicolumn{4}{|c|}{$\begin{array}{l}\text { BMI 45.0-49.9 } \\
(\mathrm{N}=27) \\
\end{array}$} & \multicolumn{4}{|c|}{$\begin{array}{l}\mathrm{BMI} \geq 50.0 \\
(N=23)\end{array}$} \\
\hline & Bias & Precision & Accuracy & $r$ & Bias & Precision & Accuracy & $r$ & Bias & Precision & Accuracy & $r$ \\
\hline $\mathrm{FFM}_{\text {[Garrow] }}$ & 3.4 & 1.9 & $90 \%$ & 0.87 & 2.6 & 2.2 & $89 \%$ & 0.78 & 2.9 & 2.1 & $100 \%$ & 0.86 \\
\hline $\mathrm{ABW}_{0.25}$ & 11.1 & 3.6 & $5 \%$ & 0.86 & 9.8 & 3.9 & $11 \%$ & 0.77 & 8.3 & 3.4 & $35 \%$ & 0.81 \\
\hline $\mathrm{ABW}_{0.5}$ & 26.1 & 3.5 & $0 \%$ & 0.87 & 27.5 & 4.4 & $0 \%$ & 0.78 & 30.4 & 2.8 & $0 \%$ & 0.87 \\
\hline LBW $_{\text {[Janmahasatian] }}$ & 4.6 & 3.2 & $65 \%$ & 0.87 & 5.4 & 3.1 & $63 \%$ & 0.77 & 7.9 & 3.8 & $35 \%$ & 0.81 \\
\hline LBW $_{\text {[Hume] }}$ & 9.4 & 4.6 & $15 \%$ & 0.77 & 16.2 & 4.3 & $0 \%$ & 0.59 & 29.7 & 7.7 & $0 \%$ & -0.01 \\
\hline $\mathrm{FFW}_{\text {[GEISINGER] }}$ & 3.2 & 1.7 & $95 \%$ & 0.87 & 2.8 & 2.0 & $96 \%$ & 0.78 & 2.6 & 1.5 & $100 \%$ & 0.87 \\
\hline
\end{tabular}

Abbreviations: ABW, adjusted body weight (kg); BMI, body mass index (kg/m²); FFM, fat-free mass (kg); FFW, fat-free weight (kg); LBW, lean body weight (kg).

shown to eliminate the bias of Cockcroft-Gault against both the creatinine and the inulin clearances when used instead of measured weight. ${ }^{7,8}$ Though this equation estimates inulin and creatinine clearance fairly well in obese populations, ${ }^{7,32}$ it did not estimate measured FFW as well as the FFM $_{\text {[Garrow] }}$ in our population of morbidly obese females. Consistent with the observation of declining performance as BMI increases for this formula, our results indicate that at incrementally higher BMI, LBW ${ }_{\text {[Janmahasatian] }}$ predicts FFW poorly. Thus, its applicability to individuals with morbid obesity may be limited.
Weight-based estimating equations had the poorest performance in our study. The ABW formulae with various correction factors - although commonly used in nutrition practice for various resting energy calculations - are based on the assumption that excess weight in obesity is linearly increased from the IBW, an assumption that is physiologically flawed. Amato et $\mathrm{al}^{33}$ evaluated the accuracy and precision of using ABW (with a correction factor of 0.5 ) in 113 morbidly obese (mean \pm SD BMI $52 \pm 9 \mathrm{~kg} / \mathrm{m}^{2}$ ) patients in a surgical intensive care unit and observed significant bias and poor precision of this body size descriptor for the prediction of

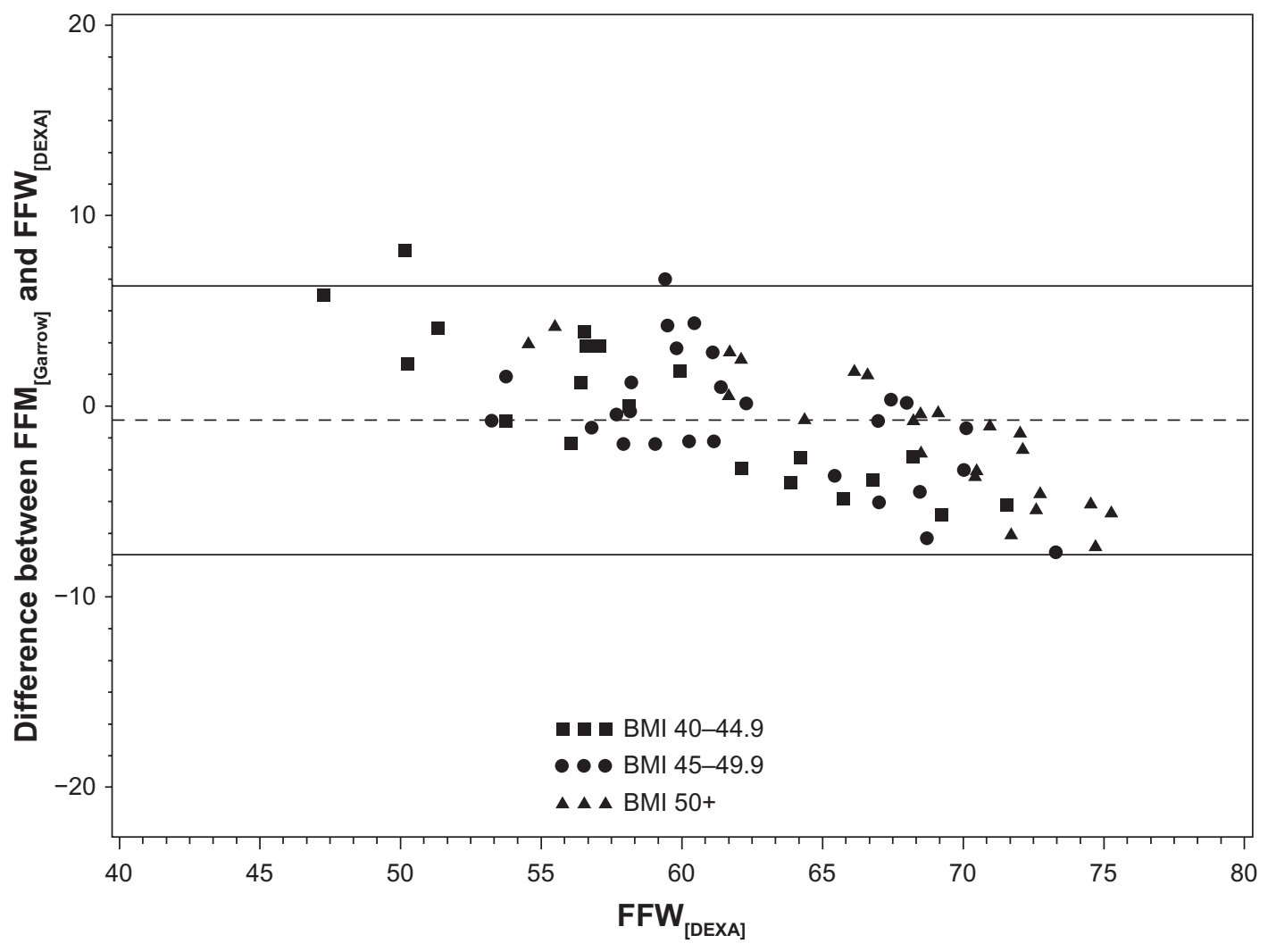

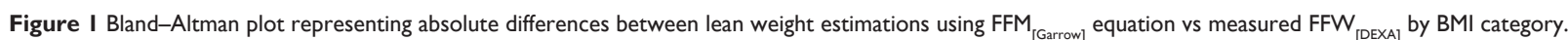
Abbreviations: BMI, body mass index $\left(\mathrm{kg} / \mathrm{m}^{2}\right)$; DEXA, dual energy absorptiometry; FFM, fat-free mass $(\mathrm{kg})$; FFW, fat-free weight $(\mathrm{kg})$. 
measured resting energy expenditure. Although a direct relationship between calorimetric testing and measured FFW cannot be assumed, our results are congruent with those of Amato et al.

The clinical significance of our study findings is illustrated by comparing the Cockcroft and Gault-estimated creatinine clearance using LBW obtained from each of the reported and derived formulae with the clearance measurement calculated using FFM from DEXA body composition scanning (Table 5). As is readily apparent, the range of calculated creatinine clearance using the various formulae is alarmingly broad. Finding and using the right lean weight estimation formula for the morbidly obese population is essential for safe health care delivery.

We derived a formula that improved the performance of FFM prediction and best approximated the estimated creatinine clearance calculation, at least among our own population of female patients with morbid obesity. This prediction formula should be tested and validated in other populations prior to clinical application.

We acknowledge that not all formulae used in our analysis were originally developed to measure the same body compartment, especially formulae such as ABW with various $\mathrm{CF}$. Although this can explain the bias, it cannot account for the poor precision and accuracy in predicting $\mathrm{FFW}_{[\mathrm{DEX}]}$. Our intention was to evaluate previously reported formulae developed to estimate alternative body weight descriptors for their potential to predict FFW in a population of morbidly obese females. The goal was not to assess the performance of these equations for their original intent. Also, our study population consists exclusively of Caucasian females, and the findings of this analysis should not be extrapolated to other patient populations without further analysis.

Table 5 Estimated creatinine clearance using the method of Cockcroft and Gault and LBW derived from DEXA and six alternative body size descriptor equations for a population of extremely obese females $(n=70)$

\begin{tabular}{ll}
\hline & $\begin{array}{l}\text { Mean (SD) estimated creatinine } \\
\text { clearance, } \mathbf{m L} / \mathbf{m i n}\end{array}$ \\
\hline $\mathrm{FFW}_{[\mathrm{DEXA}]}$ & $98.5(27.9)$ \\
$\mathrm{FFM}_{[\text {Garrow] }}$ & $97.1(26.5)$ \\
$\mathrm{ABW}_{0.25}$ & $113.1(30.7)$ \\
$\mathrm{ABW}_{0.5}$ & $141.9(39.4)$ \\
$\mathrm{LBW}_{\text {[anmahasatian] }}$ & $89.3(23.7)$ \\
$\mathrm{LBW}_{\text {[Hume] }}$ & $68.1(19.1)$ \\
$\mathrm{FFW}_{\text {[GEISINGER] }}$ & $98.3(27.5)$ \\
\hline
\end{tabular}

Abbreviations: $\mathrm{ABW}$, adjusted body weight $(\mathrm{kg})$; DEXA, dual energy absorptiometry; FFM, fat-free mass (kg); FFW, fat-free weight $(\mathrm{kg})$; LBW, lean body weight $(\mathrm{kg})$.

\section{Conclusion}

In summary, our study describes the performance of several formulae for the estimation of FFW measured by DEXA body composition scanning in a cohort of morbidly obese females. The FFM ${ }_{[\text {Garrow }}$ equation provides the best estimation of the measured FFM. The findings have important potential clinical implications as they relate to effective and safe medication dosing and optimal nutritional care, both for the hospitalized patient and for the morbidly obese patient managed in the outpatient setting.

\section{Acknowledgments}

We thank Ms Jamie Seiler PA-C for assistance with data extraction, and Ms Jennifer Fernandez and Dr Eric Newman MD for assistance with technical details related to DEXA body composition testing.

\section{Disclosure}

The authors report no conflicts of interest in this work.

\section{References}

1. Nguyen MT, Maynard SE, Kimmel PL. Misapplications of commonly used kidney equations: renal physiology in practice. Clin $J \mathrm{Am}$ Soc Nephrol. 2009;4:528-534.

2. Stevens LA, Coresh J, Feldman HI, et al. Evaluation of the modification of diet in renal disease study equation in a large diverse population. J Am Soc Nephrol. 2007;18:2749-2757.

3. Stevens LA, Coresh J, Greene T, Levey AS. Assessing kidney function: measured and estimated glomerular filtration rate. $N$ Engl $J$ Med. 2006;354:2473-2483.

4. Hudson JQ, Mason DL, Huch KM. Estimates of kidney function in obese African Americans with chronic kidney disease. Nephron Clin Pract. 2010;118:c101-c108.

5. Levey AS, Bosch JP, Lewis JB, et al. A more accurate method to estimate glomerular filtration rate from serum creatinine: a new prediction equation. Modification of Diet in Renal Disease Study Group. Ann Intern Med. 1999;130:461-470.

6. Cockcroft DW, Gault MH. Prediction of creatinine clearance from serum creatinine. Nephron. 1976;16:31-41.

7. Demirovic JA, Pai AB, Pai MP. Estimation of creatinine clearance in morbidly obese patients. Am J Health-Syst Ph. 2009;66:642-648.

8. Janmahasatian S, Duffull SB, Chagnac A, et al. Lean body mass normalizes the effect of obesity on renal function. Br JClin Pharmacol. 2008;65:964-965.

9. Forbes GB, Welle SL. Lean body mass in obesity. Int $J$ Obes. 1983;7:99-107.

10. Ravussin E, Lillioja S, Anderson TE, et al. Determinants of 24-hour energy expenditure in man. Methods and results using a respiratory chamber. J Clin Invest. 1986;78:1568-1578.

11. Bosy-Westphal A, Later W, Hitze B, et al. Accuracy of bioelectrical impedance consumer devices for measurement of body composition in comparison to whole body magnetic resonance imaging and dual X-ray absorptiometry. Obes Facts. 2008;1:319-324.

12. Kelly TL, Wilson KE, Heymsfield SB. Dual energy x-ray absorptiometry body composition reference values from NHANES. PLOS ONE. 2009;4:e7038.

13. Green B, Duffull SB. What is the best size descriptor to use for pharmacokinetic studies in the obese? Br J Clin Pharmacol. 2004;58:119-133. 
14. Garrow JS, Webster J. Quetelet's index (W/H2) as a measure of fatness. Int J Obes. 1985;9:147-153.

15. Karkeck J. Adjusted body weight for obesity. American Dietetic Association Renal Dietitians Practice Group Newsletter. 1984;3:6.

16. Cutts ME, Dowdy RP, Ellersieck MR, Edes TE. Predicting energy needs in ventilator-dependent critically ill patients: effect of adjusting weight for edema or adiposity. Am J Clin Nutr. 1997;66:1250-1256.

17. Duffull SB, Dooley MJ, Green B, et al. A standard weight descriptor for dose adjustment in the obese patient. Clin Pharmacokinet. 2004;43:1167-1178.

18. Janmahasatian S, Duffull SB, Ash S, et al. Quantification of lean bodyweight. Clin Pharmacokinet. 2005;44:1051-1065.

19. Hume R, Weyers E. Relationship between total body water and surface area in normal and obese subjects. J Clin Pathol. 1971;24:234-238.

20. Womersley J, Boddy K, King PC, Durnin JV. Estimation of the fat-free mass of twenty subjects from measurements of total body potassium, body density, skinfold thickness, and height and weight. Proc Nutr Soc. 1972;31:35A.

21. Moore F, editor. Total body cell mass and its supporting environment. Philadelphia, Pa: W.B. Saunders Company; 1963.

22. Seiler J, Wood GC, Newman E, et al. Changes in bone mineral density and body composition following Roux-en-Y gastric bypass surgery. Surg Obes Relat Dis. 2009;5:S33.

23. Benotti PN, Still CD, Wood GC, et al. Preoperative weight loss before bariatric surgery. Arch Surg. 2009;144:1150-1155.

24. Park AM, Storm DW, Fulmer BR, et al. A prospective study of risk factors for nephrolithiasis after Roux-en-Y gastric bypass surgery. J Urol. 2009;182:2334-2339.
25. Chu X, Erdman R, Susek M, et al. Association of morbid obesity with FTO and INSIG2 allelic variants. Arch Surg. 2008;143:235-240.

26. Still CD, Benotti P, Wood GC, et al. Outcomes of preoperative weight loss in high-risk patients undergoing gastric bypass surgery. Arch Surg. 2007;142:994-998.

27. Benotti P, Wood GC, Still C, et al. Obesity disease burden and surgical risk. Surg Obes Relat Dis. 2006;2:600-606.

28. Devine D. Case study number 25 gentamicin therapy. Drug Intell Clin Pharm. 1974:650-655.

29. Glynn CC, Greene GW, Winkler MF, Albina JE. Predictive versus measured energy expenditure using limits-of-agreement analysis in hospitalized, obese patients. JPEN. 1999;23:147-154.

30. Bland JM, Altman DG. Statistical methods for assessing agreement between two methods of clinical measurement. Lancet. 1986;1:307-310.

31. Levey AS, Bosch JP, Lewis JB, et al. A more accurate method to estimate glomerular filtration rate from serum creatinine: a new prediction equation. Modification of Diet in Renal Disease Study Group. Ann Intern Med. 1999;130:461-470.

32. Pai MP. Estimating the glomerular filtration rate in obese adult patients for drug dosing. Adv Chronic Kidney D. 2010;17:e53-e62.

33. Amato P, Keating KP, Quercia RA, Karbonic J. Formulaic methods of estimating calorie requirements in mechanically ventilated obese patients: a reappraisal. Nutr Clin Pract. 1995;10:229-232.

\section{Publish your work in this journal}

The International Journal of Nephrology and Renovascular Disease is an international, peer-reviewed open-access journal focusing on the pathophysiology of the kidney and vascular supply. Epidemiology, screening, diagnosis, and treatment interventions are covered as well as basic science, biochemical and immunological studies. The journal welcomes original research, clinical studies, reviews \& evaluations, expert opinion and commentary, case reports and extended reports. The manuscript management system is completely online and includes a very quick and fair peerreview system, which is all easy to use. Visit http://www.dovepress.com/ testimonials.php to read real quotes from published authors. 